\title{
An update on WPHNA participation in food security and other topics at FAO
}

For the last couple of years, our external affairs secretariat has been participating in activities of the Civil Society Mechanism (CSM) of the Committee of Food Security (CSF) of FAO. This has included frequent zoom meetings and preparation of quite a few position papers and declarations highlighting the position of participating public interest civil society organizations (PICSOs), social movements and networks.

This PICSOs active participation in a UN agency is quite unique, since we do have voice and some influence there. (Earlier, this used to be only the case in the UN System Standing Committee on Nutrition, the UNSCN.) I say 'some', because member states are the ultimate decision-makers and our criticisms and positions are often not taken into account in final decisions, official documents, etc. As has been said, "the technical is, more and more, excluding the political." It also has to be said that the price for creating the CSM was the creation of a Private Sector Mechanism (PSM) with equal participation prerogatives in the debates. I do not have to tell you how this is a clear example of corporate meddling.

Chronologically, the CSM was for three years involved in the negotiations of Voluntary Guidelines of Food Systems

(http://www.fao.org/fileadmin/templates/cfs/Docs2021/Documents/CFS_VGs_Food_System s_and_Nutrition_Strategy_EN.pdf). These negotiations were so disappointing that, towards the end, CSM set some red lines it would not negotiate on. The latter were ignored, so about a month before the Guidelines were finally approved by the member states --in steamroller fashion-- CSM publicly withdrew from the process. Therefore, the Guidelines now launched do not have the backing of the many groups representing hundreds of thousands of claim holders whose right to nutrition is being violated the world over.

Towards the end of the above negotiations, the Secretary General of the UN, following a suggestion of the World Economic Forum (Davos), called for a Food Systems Summit (FSS) to be held in October, 2021. Of course, CSM (and WPHNA) got involved in this debate. If we thought that the Guidelines were the result of a flawed process, discussions so far about the Summit have been even worse. The mechanisms and processes set up in preparing for it are flagrantly captured by corporations. In this case, CSM did not even enter the negotiations; it abstained upfront, not only providing heavy-weight objections, but also, in October 2020, sending out a call to the entire civil sector not to participate, as summarized here:

This is an open invitation to join a process of building joint strategies to counter the FSS. It is launched by organizations of those most affected by hunger, malnutrition and ecological destruction. They all participate in the Civil Society Mechanism (CSM) of the CFS of FAO. What unites them is their vision of the need to democratize food policy making and to strengthen food sovereignty as a central element of their vision. For it, they have been fighting for decades to defend food as a fundamental human right. The organizers of this call object to the FSS from its very genesis, the way it was politically framed and the governance it has given itself since all these do not correspond to the rights-based, legitimate and inclusive multilateral policy processes required to justify the name of a 'summit'. So, the call is to join 
forces into a collective process to challenge the FSS. We believe it is important to organize ourselves on our own, independently from the Summit, and to create our autonomous space to deepen our analyses, articulate our proposals and mobilize for our solutions. We, therefore share the overall vision to transform industrial food systems around key pillars, namely: Food is a fundamental right rather than a commodity; Food Sovereignty (this asserts the rights of peoples, nations and states to define their own food, agriculture, livestock and fisheries systems, and to develop policies on how food is produced, distributed and consumed); Agroecology (agroecology is a way of producing food, a way of life, a science, and a movement for change encompassing socio-economic, socio-political, and biological/ecological and cultural dimensions); Holistic Food Systems (systems that move beyond agricultural productivism and reclaim food systems as public goods that cannot be left to marketbased solutions only); Governance of Food Systems (The transformation of food systems is not possible without transforming the global and local governance of food systems).

In the way forward to challenge the FSS, we invite other movements, networks and organizations denouncing corporations' efforts to undermine human rights, disrupt territories and communities, and capture legitimate democratic spaces for private interests. There is no predetermined format for the range of potential actions and we look forward to imagining together old and new forms of mobilization, campaigning and advocacy. This call will remain open, so contact us at the following email address: call4actionfss@gmail.com

Members of the CSM had earlier, in March, 2020, written a letter to the Secretary General (SG) signed by over 500 organizations. The letter protested the appointment of the president of the Alliance for a Green Revolution in Africa (AGRA) as the summit's Special Envoy. This contradicted the innovative spirit of the summit, since AGRA is an alliance that promotes the interests of transnational corporations involved in industrial agriculture, fishing and livestock. They are responsible for destroying ecosystems; grabbing land, water and natural resources; in other words, undermining the livelihoods of indigenous peoples and rural communities by perpetuating exploitative working conditions, creating health problems, and generating significant additional quantities of greenhouse gas emissions. The SG was reminded that family farmers produce more than $80 \%$ of the world's food in value terms so that they should be at the center of the UN Food Systems Summit as had originally been the call of the UN Committee on World Food Security (CFS) and of FAO --both mandated to end hunger and malnutrition and doing so with clear policies for engagement with public interest civil society. The letter ended with a call to the SG to revoke the UN-World Economic Forum (WEF) partnership agreement and to rethink the organization of the Food System Summit to give it a truly democratic, transparent and transformative format. Till today, this letter has gone unanswered.

All efforts by the FSS secretariat to 'accommodate' us were deemed totally insufficient. FSS is now calling for a 'pre-summit' in mid-July to fine-tune the positions it is putting forward-the vast majority of which have serious conflicts of interest and paint a future with a greater role for agribusiness. (This applies to all sub-committees set up for coming up with positions.) Given this fait-accompli, CSM has decided to call for a parallel pre-summit for the same date. Regional committees have been set up in all geographical regions and a communications campaign has been set up (WPHNA has joined this communications group and WPHNA members are welcome to join by writing to email address above). Each region 
will agitate to denounce the real intentions of the FSS that, as said, foster corporate interests. In short, no CSM members will participate in FSS and all will disseminate our own vision on food systems.

As we are writing this update, UN Nutrition (which consists of the UNSCN combined with the industry-compromised SUN Initiative) has called for critiques on the first five years of the Decade on Nutrition and comments on where the focus should be for the next five years. CSM, of course, will collectively participate. A series of zoom meetings are now going on to come up with a joint response--not precluding that each member organization submits its own comments!

It has to be noted that WPHNA had a position paper exactly on this to be presented at our March 2020 conference in Brisbane. The EC of WPHNA has now decided to use it as an updated basis to prepare a possible contribution to the consultation, and it is published separately in this issue of WN.

Claudio Schuftan

External Affairs Secretary 